\title{
As fontes do espaço político técnicas eleitorais e práticas deliberativas nas cidades italianas (séculos XII - XIV)*
}

\author{
The sources of political space \\ electoral techniques and deliberative practices \\ in Italian cities (12 ${ }^{\text {th }}$ to $14^{\text {th }}$ centuries)
}

\section{Aux sources de l'espace politique techniques électorales et pratiques délibératives dans les cités italiennes (XII -XIV siècles)}

PATRICK GILLI Universidade de Montpellier III 2 Place Pétrarque 34000 Montpellier, France patrick.gilli@univ-montp3.fr

RESUMO Para quem pesquisa, nas práticas usuais da ldade Média, os vestígios de um espaço de mediação política, o mundo das comunas italianas dos séculos XII-XIV oferece um laboratório privilegiado de observação. O desenvolvimento de instituições representativas (conselhos "legislativos" e colégios "executivos") se caracterizou pela utilização de técnicas de seleção de pessoal dirigente destinadas a evitar o monopólio de algumas famílias

Artigo recebido em 07/05/2010. Autor convidado. 
e a garantir a rotatividade das atribuições no seio das classes dirigentes. $O$ presente artigo examina as fontes, notadamente estatutárias, que definem as modalidades de representação dos cidadãos chamados a governar ou a tomar decisões. Ele retoma a cronologia de instauração do princípio de representação que se impõe sobre o de unanimidade. Examinando igualmente os processos eleitorais, ele busca precisar o que os contemporâneos desejavam valorizar por meio da seleção eleitoral dos governantes. Uma atenção particular é dada às questões materiais dos votos e dos escrutínios (segredo das eleições, instalação de graus eleitorais, etc.).

Palavras-chave técnicas eleitorais, comunas italianas, práticas deliberativas

ABSTRACT For those who research, in the usual practices of the Middle Ages, remains of a space of political mediation, the world of the Italian communes of the XII-XIV centuries offers a privileged laboratory of observation. The development of representative institutions ("legalislative" councils and "executive" colleges) was characterized by the use of techniques for selection of management personnel to prevent the monopoly of some families and ensure the rotation of assignments within the ruling classes. This article examines the sources, notably the statutes, which define the modes of representation of citizens called to govern or to take decisions. It uses the chronology of the introduction of the principle of representation that is imposed upon the unanimity. Examining also the elections, it seeks to clarify what contemporaries desired to value by selecting the rulers using this system. Particular attention is given to the substantive issues of the votes and ballots (secret elections, electoral installation of degrees, etc.)

Keywords electoral techniques, Italian communes, deliberative practices

RÉSUMÉ Pour qui recherche dans les pratiques ordinaires du Moyen Âge, les traces d'un espace de médiation politique, le monde des communes italiennes des XIIe-XIVe siècles offre un laboratoire privilégié d'observation. Le développement d'institutions représentatives (conseils "législatifs" et collèges "exécutifs") s'est opéré par l'utilisation de techniques de sélection du personnel dirigeant destinées à éviter le monopole de gouvernement par certaines familles et la rotation des charges au sein des classes dirigeantes. Le présent article interroge les sources, notamment statutaires, qui définissent les modalités de représentation des citoyens appelés à gouverner ou à prendre les décisions. II reprend la chronologie d'instauration du principe de représentation qui s'impose sur celui d'unanimité. En examinant également les procédures électorales, il cherche à préciser ce que les contemporains désiraient mettre en valeur à travers la sélection électorale des gouvernants. 
Une attention particulière est portée aux questions matérielles des votes et des scrutins (secret des élections, mise en place de grades électoraux, etc.).

Mots clefs techniques électorales, communes italiennes, pratiques délibératives

Ao pesquisar a singularidade do fato político italiano, encontramos rapidamente uma prática que deixou vestígios importantes na vida política da época: as deliberações comunais e seu corolário - os processos eleitorais que viabilizavam a participação na atividade deliberativa local. Poderíamos, claro, objetar facilmente que as cidades italianas estão longe de terem sido as únicas a implantar regimes (parcialmente) representativos e instituições deliberativas. ${ }^{1}$ Todas as cidades européias, e mesmo os povoados, tiveram representantes e conselhos, em número e tamanho variáveis. Para dar um exemplo na França, a cidade de Montpellier, na Idade Média, adotou uma surpreendente técnica de designação desses conselheiros, técnica cuja complexidade não teve muito o que invejar daquelas das cidades peninsulares. ${ }^{2}$ De onde vem, então, a eventual singularidade italiana nesta área? De um lado, menos, provavelmente, do refinamento dos procedimentos, ainda que estes sejam com frequência impressionantes, ${ }^{3}$ que da importância que obtiveram na vida deliberativa - e, portanto, no espaço político por excelência - a reflexão e os debates sobre esses procedimentos - testemunhos particularmente marcantes dos conflitos tanto ideológicos quanto sociais na definição do perímetro de uma cidadania ativa. De outro lado, os métodos de seleção ou de acesso ao poder de elites dirigentes. Podemos observar que para cada acontecimento político que afeta uma cidade corresponde uma reforma eleitoral, como se fosse impossível distinguir a orientação política dos processos de deliberação e de seleção do pessoal administrativo e político.

1 Para a França, ver FARGEIX, C. Les élites lyonnaises au miroir de leur langage. Recherches sur les pratiques et les représentations culturelles des conseillers de Lyon du XVe siècle, d'après les registres des délibérations consulaires. Universidade Lyon 2, 2005. (História, Tese de doutorado) e FARGEIX, C. La reconnaissance des délibérations lors des assemblées lyonnaises, dans les registres consulaires du XVe siècle: un problème politique. Disponível no site do Lamop : http://lamop.univ-paris1.fr/W3/espacepublic/Espace\% 20public\% 2013.12.rtf.

2 Sobre um estudo que renovaria essa abordagem, ver BAUMEL, J. Histoire d'une seigneurie du midi de la France. Montpellier sous la seigneurie de Jacques le Conquérant et des rois de Majorque, rattachement de Montpelliéret, 1293, et de Montpellier, 1349, à la France. Montpellier, 1971, t. II, p.45-50.

3 Basta pensar que a reforma veneziana de 1268, como é descrita por Andrea Dandolo, introduz no seio do grande Conselho nove colégios de eleitores, que formam o mesmo número de graus eleitorais sucessivos, antes da eleição do doge. Ver DANDOLO, Andrea. Venetiarum chronica par extensum descripta. In: PASTORELLO, E. (ed.) Rerum Italicarum Scriptores. $2^{\mathrm{a}}$.ed. Bologna, v.12, parte 1, 1958, p.320. 
O segundo ponto a ser evidenciado neste artigo, é que, em primeiro lugar, a implantação dos processos eleitorais cívicos aproveitou a maturação das idéias eclesiológicas e canônicas sobre a eleição dos prelados, papas e bispos. Entre o mundo comunal e o mundo eclesiástico, modelos circularam nos dois sentidos, como nós tentaremos mostrar, mas a análise das noções de representação e de personalidade jurídica por parte dos canonistas não poderia ser minimizada no que diz respeito a seus efeitos sobre a prática cívica.

Uma última observação deve ser feita antes de entrar no cerne do assunto: o pesquisador que quiser aplicar uma reflexão de ciência política a estas práticas ao mesmo tempo deliberativas e eletivas, se choca com o estranho silêncio das fontes. Logicamente os estatutos urbanos detalham da melhor maneira possível os processos eleitorais, mas os pensadores do político nunca os consideraram em si como determinantes: ${ }^{4}$ bastava que se estabelecesse sua existência para que nos encontrássemos em um regime republicano - louvável ou criticável, segundo o ponto de vista dos autores medievais -, mas este desinteresse aparente pelas práticas deliberativas e os desafios dos processos eleitorais, da parte dos intelectuais, é totalmente característico e bem surpreendente, quando se compara ao interesse que os canonistas dispensaram a estes mesmos procedimentos. ${ }^{5}$ Porque a história das técnicas eleitorais mostra precisamente que não se trata somente de técnicas, mas da própria organização do regime. A natureza profunda do sistema deliberativo remete à representação do regime, ao mesmo tempo no sentido de sua encenação e de sua autodefinição funcional.

Os sistemas de deliberações coletivas oriundas da sociedade comunal evoluíram com bastante rapidez. ${ }^{6}$ Quando apareceram os regimes consulares, as técnicas representativas eram bastante embrionárias. As tomadas de decisão, mal conhecidas, pareciam requerer a unanimidade. O regime consular se fundamentava em um pacto jurado, sacramentum sequimenti, que legitimava a autoridade dos cônsules e ratificava a delegação de competências arbitrais dos cidadãos a seus representantes. Esta delegação era validada por um juramento feito por todos os homens válidos da comuna.

4 Todavia, uma exceção a esse desinteresse, os três trabalhos insólitos de ars electionis de Ramon Llull sobre os modos de cálculo eleitoral que permitiriam combinar maior et sanior pars: HÄGELE, G e PUKELSHEIM, F. Llull's writings on electoral systems. Studia Lulliana, v.41, p.3-38, 2001.

5 Não se trata de uma reflexão desencarnada. Na realidade, a igreja pós-gregoriana experimentava formas de representação e de delegação, em particular quando dos concílios, que apareciam originais e inéditas. Ver o notável estudo de caso de R. Kay, que lembra que as capítulas catedrais não eram representadas antes de 1217 e a decretal Etsi corpora membris (p.91-99) o foi no momento em que a taxação dos bens eclesiásticos exigia que as capítulas dessem sua opinião, em virtude do adágio Quod omne tangit. KAY, R. The council of Bourges, 1225. A documentary History. Aldershot: Ashgate, 2002.

6 Exemplos escolhidos do funcionamento deliberatvo, ver em SBARBARO, M. Le delibere dei Consigli dei comuni cittadini italiani: secoli XIII-XIV. Roma: Edizioni di Storia e letteratura, 2005. Dois casos particulares foram apresentados por ROSSETTI, Gabriella. Entre Pise e Milan. In: DÉTIENNE, M. (ed.) Qui veut prendre la parole? Le Genre Humain, Paris, n.40-41, p.229-242, 2003 e por REDON, O. Parole, témoignage, décision dans les assemblées communales en Toscane méridionale aux XII et XIIIe siècles. In: DÉTIENNE, M. (ed.) Qui veut prendre la parole?, p.243-255. 
Paolo Prodi lembrou a importância do juramento na cultura medieval, não somente na sua dimensão antropológica, mas, mais expressamente na jurídica: a eficácia do juramento se encontra na sua capacidade de dotar um certo grau de direito àqueles que o pronunciam. ${ }^{7}$ É uma maneira de vivificar o vínculo contratual na base da comuna. Isto era suficiente para criar uma dinâmica política na comuna? Se nos restringirmos à época consular, e se buscarmos sempre o que faz a essência do político, há uma etapa mais decisiva ainda: testemunhos particularmente eloquentes desta importância dos juramentos coletivos e completos, aparentemente sem instância representativa, emergem em acordos intercidadãos que requeriam, para serem aprovadas, listas de votantes por bairros, o que se supõe integrar a totalidade da cidadania ativa. ${ }^{8}$ É provavelmente a pressão das relações internacionais, isto é, inicialmente intercitadinas, que contribuiu para o amadurecimento dessas instituições representativas. Os tratados de aliança entre cidades, especialmente na época de Frédéric Barberousse, deviam ser validados por toda a civitas, mas, rapidamente processos de delegação emergiram, simplificaram o registro dos pactos e tornaram possíveis os desenvolvimentos das técnicas representativas. Ao longo século XIII, são os representantes da comuna, cônsules ou magistrados, que, cada vez mais, juram observar os tratados super animam populi. A emergência de um espaço do político é indissociável destas técnicas de representação e de delegação: o político pressupõe uma consciência da dualidade do cidadão, ao mesmo tempo habitante da cidade e protagonista da projeção e da organização da comuna, além do horizonte material da cidade. Tal construção - os dois corpos do cidadão/citadino -, de certa forma, foi facilitada pela extrema fragmentação dos processos associativos: a cidade italiana, não é uma massa inorgânica de habitantes que delega a representantes ad tempus a gestão dos negócios comuns, é uma extraordinária proliferação da vida associativa que duplica e reproduz, sobre bases territoriais, corporativas ou militares, o sentimento de vinculação a um corpo social. Que se trate das sociedades de armas, das sociedades "rionales", ou das sociedades de artes, em cada uma destas instâncias, o cidadão integrado aprendia sua a responsabilidade e a necessidade de delegar, provisoriamente, seu poder a terceiros. ${ }^{9}$

7 PRODI, P. I/ sacramento del potere. Roma, 1993, p.93-96. Contra todas as tolices de coloração antropológica que atravancam a historiografia política - em particular a francesa - sobre o suposto diálogo entre governantes e governados, as observações de Prodi trazem a retificação necessária e a reorientação indispensável sobre os desafios de direitos.

8 Um estudo exemplar sobre estas fontes foi conduzido por SALVATORI, E. La popolazione pisana nel Duecento. I patto di alleanza di Pisa con Siena, Pistoia e Poggibonsi del 1228. Pisa: Gisem-Edizioni ETS, 1994.

9 Essa talvez tenha sido a principal diferença com as cidades das outras áreas européias, a Renânia e Flandres especialmente. Nessas regiões, com forte desenvolvimento urbano e econômico, o jogo institucional local, mesmo tendo sido muito agitado, não se aparenta à criação de um espaço propriamente político, no sentido de uma terceira estrutura específica que viria se interpor entre os grupos sociais antagônicos. Os exemplos alemães ilustram, antes, uma forma de conquista do poder por corporações artesanais ao longo do século XIV que não 
Mas nós só estamos na primeira etapa da criação de um espaço político, isto é, de um espaço de mediação institucional dos negócios que concernem a uma coletividade como um todo. Outro processo, tão importante quanto este, merece ser descrito nesta perspectiva: a criação das assembléias deliberativas. A consistência das instituições consulares, e depois as magistrais (que vigia sobre os negócios mais variados do sistema fiscal, da guerra, do comércio e, sobretudo da justiça), sistematizou o recurso no qual assembléias delegadas (conselhos do povo ou de Crédence (confiança?) vinham duplicar, como uma estrutura tecnocrática, a assembléia geral dos cidadãos, chamada o parlamentum ou o arengo. ${ }^{10}$ Quando vemos estas assembléias funcionarem, selecionadas evidentemente segundo critérios que são vestígios dos equilíbrios sociais da comuna em um dado momento, é sempre o princípio majoritário que preside os votos. Princípio majoritário que se deve entender na sua acepção romana: "refertur ad universos quod publice fit per maiorem partem" (D.50.17.160) ou ainda "Quod maior pars curiae effecit, pro eo habetur, ac si omnes egerint" (D. 50.1.19). Legistas e canonistas se dedicaram a encontrar argumentos de uma profundidade extrema sobre estas noções que colocavam em jogo a doutrina romana da ficção e da corporação. ${ }^{11}$ Mas o essencial é compreendido pelos juristas: se a maioria representa a totalidade e a totalidade representa a pessoa jurídica, então, esta podia ser representada por sua maioria. É o que encontramos afirmado nos procedimentos eletivos das capítulas catedrais: "capitulum et maior pars sunt unum et idem". É assim também que acontece nas assembléias deliberativas cívicas, como o reporta o Bref Pisan, de 1313-1337: "quod habeat consilium robur et autoritatem et firmitatem omnimodam, perinde ac si totum comune Pisanum simul congregatum illud decrevisset et statuisset". 12 Parece que nesta área, as assembléias italianas não precisaram afinar mais sua reflexão sobre a representação. O princípio majoritário se impôs sem dificuldade e sem muita discussão, como único método capaz de ratificar vontades supostamente equivalentes e fungíveis quando, ao mesmo tempo, trazia dificuldades ao direito da igreja que oscilava perpetuamente

engendrou uma cultura da participação, da deliberação ou das formas singulares de cidadania. Ver os estudos de SZABÓ, T. Potere economico e potere politico nelle città tedesche. In: BALBI, G. Petti. (ed.) Strutture del potere ed élites economiche nelle città europei dei secoli XII-XVI Napoli: Gisem/Liguori Editore, 1996; GÖMMEL, R. Economia e politica nell'attività dei ceti imprenditoriali di Ratisbona e Norimberga nei secoli XIII-XVIII. In: BALBI, G. Petti. (ed.) Strutture del potere ed élites economiche nelle città europei dei secoli XII-XVI; POSTEL, R. Iniziative economiche e obiettivi politici dei detentori del potere e delle élites imprenditoriali, mercantili e finanziere tra XIII e XVIII secolo: l'esempio di Amburgo. In: BALBI, G. Petti. (ed.) Strutture del potere ed élites economiche nelle città europei dei secoli XII-XVI. Seguramente, a questão das singularidades políticas do espaço alemão merece aprofundamentos historiográficos.

10 Eu me permito remeter a GILLI, P. Villes et sociétés urbaines en Italie (XIle-XIVe s.). Paris: Sedes, 2005.

11 GROSSI, P. Unanimitas: alle origine del concetto della persona giuridica nello diritto canonico. Annali di Storia del Diritto, v.2, p.229-331, 1958 e GAUDEMET, J. Unanimité et majorité (observations sur quelques études récentes). Études historiques à la mémoire de Noël Didier, Paris, Montchrestien, p.149-162, 1960.

12 BONAINI, F. Statuti inediti della citta di Pisa dal XII al XIV secolo. Firenze, 1854-1870, v. II, p.17. 
entre a busca da unanimidade ${ }^{13}$ e a reivindicação de uma sanior pars em suas próprias eleições. ${ }^{14} \mathrm{O}$ direito canônico tinha, efetivamente, esvaziado de sua substância o princípio da maior pars, distinguindo entre uma maior pars respectu numeri e uma maior pars respectu consilii; em outras palavras, contrabalançando o critério quantitativo por um critério qualitativo, entretanto incompatíveis entre eles. Além do mais, muitos canonistas tardios consideram que o princípio da sanior pars não pode se aplicar às universitates saeculares, mas deve permanecer uma particularidade das corporações eclesiásticas. É o cardeal Alessandrino (Giovanni Antonio San Giorgio, elevado a cardeal em 1507), professor de direito canônico, que explica que a lei do número se aplica aos leges, pois, segundo o rigor juris que as leis devem seguir, cada homem capaz "tamquam membrum particulare universitatis par est in universitate", ${ }^{15}$ enquanto que os cânones, na busca do aequitas, devem levar em consideração o valor intrínseco do voto de cada membro. Para os canonistas medievais, o que importa é o bom resultado da eleição, ou seja, a aptidão do eleito em preencher sua função, mais que a fiel interpretação da vontade do corpo eleitoral. Daí a necessidade que os votos sejam não somente contados, mas pesados, o que é o próprio axioma da sanioritas, desde 1179 e do concílio de Latrão III. ${ }^{16}$ Não há nada (formalmente pelo menos) nos procedimentos eletivos e deliberativos das assembléias italianas que se atenha ao estrito voto majoritário que se impôs, não sem dificuldade, sobre o princípio da unanimidade. ${ }^{17}$ É no final do

13 Vários princípios patrísticos vinham justificar esta necessária unanimidade: ver Léon le Grand: Qui praefuturus est omnibus, ab omnibus eligatur. Apud: PL 54, 634; e Grégoire o Grande, In scissura mentium Deus non est. Homiliae in Evangelia, v.22, n.4, dans PL, 76, 1176. Ver BENSON, R. The bishop-elect: a study in medieval ecclesiastical office. Princeton: Princeton University Press, 1968.

14 Pra dizer a verdade, a canonística insistiu no princípio majoritário, mesmo quando algumas vozes, entre as mais eminentes, buscavam examinar este princípio. É assim que Vincentius Hispanus, um dos mais eminentes canonistas do início do século XIII, comenta o cânon 23, de Latrão IV, lembrando a opinião de Inocêncio III: "Et si maior pars uult aliunde eligere, minor preualet, etiam si sint duo, quia tunc unus potest eligere alium. Set secus dicerem si omnes consentiunt preter unum in extraneum. Tunc enim non est qui [ex app. crit.] eligat. Se enim non potest eligere et alium iam non potest, quia quilibet consentit in extraneum, et omnes preiudicant sibi. Et hec opinio domini pape, et ita intelligitur extra. iii. de elect. Cum inter dilectos". Constitutiones Concilii quarti Lateranensis una cum commentariis glossatorum. Edição de A. García y García. Città Del Vaticano, 1981, p.318. Ver PENNINGTON, K. Further thoughts on Pope Innocent III's knowledge of law. In: Popes, canonists, and texts, 1150-1550. Aldershot: Variorum, 1993. A questão em suspenso era a da eleição ou não de um bispo entre os membros da capítula catedra. Inocêncio e seus comentadores, dos quais se destaca Vincentius, sustentam que um recrutamento local, mesmo fundamentado em uma minoria de duas vozes oriundas do colégio catedral, prima na eleição de um outsider desejado por uma maioria desse conselho. Era claramente ponderado o princípio majoritário por critérios extra quantitativos. Além do mais, grande parte da canonística não seguiu Inocêncio III neste ponto e fez prevalecer o critério da maior pars.

15 Johannes Antonius < de Sancto Georgio > Commentaria super decreto cardinalis alexandrini alias Prepositi Sancti Ambrosii nu[n]cupati - [Electronic ed.]. - Venetiis, Stagninus, 1500. Permalink: http://diglib.hab.de/inkunabeln/117-jur-2f/start.htm. Trata-se de um comentário em c.6 D.19.

16 Um notável estudo de caso, entre elaboração doutrinal e conflitos locais, na escala da diocese de Rouen, fo começado por Jörg Peltzer, que examina a recepção e a adaptação dos cânones conciliares na articulação dos séculos XII - XIII. PELTZER, J. Conflits électoraux et droit canonique. Le problème de la valeur des votes lors des élections épiscopales en Normandie au Moyen Âge central. In: La résolution des conflits et l'écrit, Tabularia, Revue en ligne, 2005. http://www.unicaen.fr/mrsh/crahm/revue/tabularia/peltzer.html].

17 As resistências ao fim da unanimidade encontram exemplo nos protestos emitidos em 1237 por um dos eleitores do magistrado de Gênova. Descontente com a escolha majoritária, ele protesta veementemente e confia a decisão ao arcebispo e a sábios que finalmente validaram a eleição do magistrado: Annali Genovesi di Caffaro e de' suoi continuator. Edição de C. Imperiale di Sant'Angelo. Roma, 1923, p.186: "Ipso quidem anno de regimine civitatis 
século XII que vemos aparecer nas fontes a expressão de maior pars, ou de maior et melior pars como referências a procedimentos eleitorais. Todo um léxico eleitoral se difunde nos centros menores, como num auto de venda encetado pelos habitantes do povoado de Lucquesonde, entre 1141 e 1159, de um castelo e das terras de San Gervasio localizados nas imediações, onde toda uma terminologia técnica do voto é apresentada: partito facto inter eos, eorum nemine discrepante, ratifica-verunt, etc. ${ }^{18}$ Precisemos que este registro dos procedimentos deliberativos concerne somente aos conselhos já eleitos e não às assembléias plenárias (arengo ou concio) nas quais somente a aprovação pelo grito é praticada. ${ }^{19}$ Esta é, aliás, a forma tradicional de aprovação, a qual se dirigem reprovações doravante célebres de Boncompagno da Signa, intelectual aristocrático, em sua Rhetorica Novíssima, que vilipendia os contionatores desejosos de lisonja. ${ }^{20}$ Mas, ao

Janue, quinque ex electoribus eligerunt pro anno venturo D. Paulum de Surexina civem Mediolanensem in potestatem Janue, et unus ex electoribus noluit consentire ipsi electioni, et exinde crevit dissensio inter cives Janue, qui quidem dicebant quod electio non tenebat". É preciso citar igualmente a passagem dos estatutos de Chieri, de 1311, que prescreve punir aquele dos quatro cônsules que se opusessem à opinião dos três outros: "quotienscumque quatuor consules fuerint in dicta societate et tres ipsorum fuerint in concordia aliquid faciendi quod quicquid factum fuerit per predictos tres sit validum et firmum et nullo modo possit removeri et vox illius quarti qui nollet id quod alii vellent non valeat ymo sit cassa et nullius valoris et incurrat ille quartus penam nihilominus librarum vigintiquinque". Historiae Patriae Monumenta. Torino, 1896, Leges municipales, II, col. 760 (doravante HPM).

18 Texto em Memorie e documenti per servire all'istoria di Lucca V (Lucca 1837/44) 325 sq.: "omnes de comune S. Gervasii, qui sunt maior, melior et sanior pars (...) at que due partes de tribus (...) personarum suprascripti comunis, coadunati ad consilium in suprascripta canonica, partito facto inter eos, eorum nemine discrepante (...) ratificaverunt". Cf. RUFFINI, Edoardo. I sistemi di deliberazione collettiva nel medioevo italiano. In: La ragione dei più. Torino 1927; reéd. 1977, p.229 (obra sempre fundamental).

19 Ver: DELUMEAU, J-P. De l'assemblée précommunale au temps des conseils. Em Italie centrale. In: DÉTIENNE, M. (ed.) Qui veut prendre la parole?, p.212-228.

20 BONCOMPAGNO DA SIGNA. Rhetorica Novíssima. Edição de S. Wight. Los Angeles, 1998: "13.1.4. Contionator est, qui sicut tuba exaltat vocem suam super agmina populorum. Officium contionatoris est adulari, interponere mendacia palliata et uti persuasionibus deceptivis. Consuetudo contionandi viget in civitatibus et oppidibus Italie propter eximiam libertatem. 13.1.5 Quot sunt que impediunt contionem. 13.1.10 Narratio doctrinalis. Omnes contionatores habent contionandi scientiam magis per consuetudinem quam naturam, quia non potest esse scientia naturalis, maxime cum verba contionatorum in abusionem et aperta mendacia dilabuntur, nec esse valet, quod aliquando non referant veritatem. 13.1.11 De moribus contionatorum. Mos contionatorum est ascendere in spectaculum et in gestibus corporum ostendere venustatem. Petunt in primis, ut eis audientia et intelligentia prebeantur et infulati precones non desinunt proclamare dicentes 'audi, audi'. Postea Deum omnipotentem et ipsius matrem Virginem gloriosam et illius apostoli vel sancti merita, quem cives aut habitatores locorum patronum reputant et tutorem, exorant, ut illa contio ad honorem et statum militie atque populi debeat multimode pertinere. Insistunt postea laudibus venativis et civitates aut oppida vel personas magnificis extollunt preconiis et exaltant. Postea incipiunt specificare materiam pro qua fit contio et nituntur militibus atque populo iuxta beneplacitum suadere. Si vero contionator ex officio teneatur sumere de aliquibus ultionem vel ad faciendum exercitium intendat militiam et populum animare, ascendit dextrarium in montem, qui terram videtur in fremitu conculcare, super quem sedet accinctus gladio, terribilem ostendit faciem, supercilia elevat, extendit cyra et pedes in streupis, agitat calcaria, brachium elevat ad suprema, dextra manu innuit, voce hortatur, infert minas, reducit ad memoriam facta clarissima et victorias antiquorum. In fine siquidem cuiuslibet contionis quilibet contionator persuadet turbis et agminibus populorum, ut de his que retulit suam debeant ostendere voluntatem. Unde omnes et singuli tumultuosos clamores emittunt, pallia elevant et reflectunt, et altius proclamantes dicunt: 'fiant, fiant'. Verum quia contionandi officium rarissime ad viros pertinet litteratos, idcirco hec plebia doctrina est laicis Italie reliquenda, qui ad narrandum magnalia contionum a sola consuetudine sunt instructi". ("A contio é a reunião do povo que, seguindo o costume da cidade ou do lugar, se reúne ao clamor dos trompetes ou ao som dos sinos. O contionator é aquele que, como um trompete, exalta sua voz acima dos grupos dos populares. $\mathrm{O}$ oficio do contionator é de lisonjear, de pronunciar mentiras bem mascaradas e de se servir de uma persuasão enganadora. O costume da contio está em vigor nas cidades e em outros lugares da Italia por causa de sua grande liberdade. (...) Todo contionator finalmente exige da multidão e do grupo dos populares que exprimam sua vontade sobre o que ele acaba de dizer. Neste momento, todos e cada um explodem em clamores tumultuosos, agitam de cima a baixo as bandeiras e gritam em voz muito alta 'Assim seja ! Assim seja!' Mas é extremamante raro que os homens letrados se encarreguem da contio: é preciso deixar este saber plebeu às pessoas não letradas da Italia que, por eles mesmos, aprenderam a tratar de grandes assuntos". Ver: GERBIER, L. Parler au peuple: la pratique de la contio de l'Antiquité à la Renaissance. Erytheis, v.1, 2005. (http://www.erytheis.net/texte-integral. 
mesmo tempo, este mesmo letrado aristocrático reconhece que a contio existe porque as cidades italianas são lugar de notável liberdade, ${ }^{21}$ fazendo assim a ligação, bem a contragosto, entre os processos de falar em público e a existência de condições políticas apropriadas.

É impressionante que nos estatutos urbanos do século XIII, os redatores concederam um lugar desmesurado às questões de designação das magistraturas e dos ofícios municipais, desenvolvendo procedimentos muito mais refinados que os da antiguidade, ${ }^{22}$ enquanto que as questões sobre a própria deliberação, sobre questões centrais inclusive, não são muito abordadas. ${ }^{23}$ No entanto, a própria existência de instâncias deliberativas não pode ser neutra em relação ao próprio funcionamento público. A sociologia da decisão demonstrou claramente que as idéias e a deliberação podem exercer influência nas decisões públicas quando a confrontação dos interesses é temperada pela própria natureza do objeto das decisões. "As idéias são impotentes se a política é um jogo empatado". ${ }^{24}$ Mas se as decisões têm por objeto o problema da eficácia das políticas, notadamente sobre sua capacidade de produzir o bem estar geral, mais que a distribuição das riquezas, que beneficiará uns grupos em detrimento de outros, o jogo não está empatado. Mesmo se podendo esperar que o bem coletivamente produzido seja distribuído de maneira a satisfazer todo mundo, há um interesse comum pelo aumento da eficácia da política, de onde nasce a possibilidade que a deliberação intervenha na formação de novas proposições. É então impressionante constatar que por meio da figura do magistrado, as cidades italianas descobriram empiricamente princípios que autorizam o funcionamento das instâncias deliberativas, em particular a figura de um terceiro, exterior ao desafio. ${ }^{25}$ Não é, por acaso, portanto, que a cultura do bem comum, pelo menos na sua expressão retórica, pôde se desenvolver nos conselhos da Itália comunal. ${ }^{26}$

php3?id_article=65); sobre o personagem, ver BALDINI, M. (ed.) // pensiero e l'opera di Boncompagno da Signa. Firenze: Signa, 2002

21 BONCOMPAGNO DA SIGNA. Rhetorica Novissima 13.1.4: "Consuetudo contionandi viget in civitatibus et oppidibus Italie propter eximiam libertatem".

22 Para uma apresentação detalhada do sistema romano, ver NICOLET, C. Le métier de citoyen dans la Rome républicaine. Paris: Gallimard, 1988.

23 Un dos primeiros historiadores a se interessar por este problema tinha observado esta relativa indiferença. WOLFSON, A. The ballot and other forms of voting in the Italian communes. American Historical Review v.5, p.1-21, 1899, especialmente p.6.

24 MAJONE, G. Décisions publiques et délibération. Revue Française de Science Politique, v.44, n.4, p.579-598, agosto 1994. O autor postula que a deliberação é possível se os participantes da decisão debaterem entre si os melhores meios para produzir os bens e é impossivel quando o desafio é a distribuição destes bens. Cf. URFALINO, Ph. La délibération n'est pas une conversation. Délibération, décision collective et négociation, Négociations, n.4, p.99-144, 2005. (disponivel on line: http://lodel.ehess.fr/cesta/document.php?id=182). Não se tem, aí, uma das chaves do dispositivo deliberativo comunal?

25 URFALINO, Ph. La délibération et la dimension normative de la décision collective. In: COMMAILLE, J.; DUMOULIN L. e ROBERT, C. (eds.) La juridicisation du politique. Paris: LGDJ, 2000, p.165-193; Cf. ELSTER, J. La délibération et la dimension normative de la décision collective. Revue Française de Science Politique, v.44, n.2, p.187-257, abril 1994.

26 Segundo Urfalino, "a deliberação não é uma conversação"; "a influência do egoismo é, de uma forma ou de outra diminuída (preocupação voluntária ou forçada do bem comum, reflexão sobre o bem comum)". Sobre este tema, 
Da mesma maneira que as práticas representativas conferiram um peso crescente à maior pars, assistimos a uma evolução clara nas formas de voto. Enquanto prevalecia a busca do consenso e da unanimidade, predominava um procedimento dito per disces-sionem, que consistia em se reagrupar de um e outro lado da assembléia segundo a aprovação ou a recusa do projeto. Mais técnicas, as decisões ad levandum et sedendum, já implicavam em uma contagem dos votos. Aliás, os estatutos de Bolonha, de 1250, previam a sobreposição das operações: começa-se por um procedimento ad levandum et sedendum e se os resultados não parecerem claros o bastante, procedia-se a um novo voto per discessionem. ${ }^{27}$ Mas, como regra geral, exceto para os votos secretos, era o processo ad levandum et sedendum que teria se tornado a regra usual na Itália. ${ }^{28} \mathrm{Um}$ processo que, todavia, de forma alguma era simples, pois, na realidade, era necessário votar duas vezes, uma vez para aqueles que se levantavam e outra vez para os que ficavam assentados: as fontes batizam esta dupla etapa de facto et revoluto partito (o voto tendo sido feito e refeito). ${ }^{29} \mathrm{~A}$ existência desta técnica já é indicativa do amadurecimento das práticas políticas, pois isto indica, contrariamente à velha cultura do consenso e da aprovação, que eram contados também os oponentes (observemos na passagem que, se conhecemos o grito de aprovação dos projetos - fiat, fiat -, não conhecemos o da divergência, provavelmente porque ele não tinha seu lugar nas assembléias deliberativas). A emergência desta técnica revela as tensões do corpo cívico e sua vontade de brigar na arena política. ${ }^{30}$ Mas a oposição ainda continuava a descoberto. A importância das dissensões e a vontade de avançar sem temer represálias incitaram as cidades a sempre avançar na criação de práticas de voto secreto. Encontramos, já no início do século XIII, um primeiro processo: da boca ao ouvido (ore ad os). Trata-se de uma prática em que cada conselheiro se levantava e ia colocar sua deliberação verbalmente junto a um terceiro, frequentemente um eclesiástico, que então registrava os votos por escrito. ${ }^{31}$ Mas é, evidentemente, a prática do scrutinium, do voto secreto, que ajudou a transpor uma etapa na elaboração,

ver KEMPSHALL, M. S. The common good in Late Medieval political thought. Oxford: Oxford University Press, 1999.

27 FRATI, L. (éd.) Statuti di Bologna dallanno 1245 all'anno 1267. Bologna 1869, tomo I, v.1, p.68: "secundum dicta constitutionum faciam partita, et si dubitarem de partitis revolvam partita, et unam partem faciam ab uno latere palatii et aliam ab alio latere et faciam eos numerari per meos familiares".

28 Um exame dos procedimentos eleitorais em KELLER, $\mathrm{H}$. Wahlformen und Ge-meinschaftsverständnis in den italienischen Stadtkommunen (12./14. Jahrhun-dert). In: SCHNEIDER, R. e ZIMMERMANN, H. (eds.) Wahlen und Wählen im Mittel-alter. Sigmaringen, 1990, p.345-374

29 Os estatutos de 1254 lembram que somente o resultado do segundo turno de votação valida a decisão: "Potestas teneatur et debeat facere partitam revolvendo eam, ita quod illud partitum quod semel posuerit ad sedendum, iterato ponat ad levandum, et quod solum illud partitum reformetur... quod obtinebit in revolutione": HPM, Leges municipales, col.1584.

30 Não é, aliás, por acaso que, como regra geral, a aprovação se fazia ficando assentado e a reprovação, se levantando. A desavença tem interesse comum com a contestação e o tumulto, que se tornam visíveis quando os protestadores se levantam

31 Ver os estatutos de Brescia de 1217: HPM, I. II. Ver RUFFINI. La ragione dei più, p.252. 
senão de um direito da minoria, pelo menos de um direito estabelecido na divergência. A necessidade do segredo é justificada expressamente pelo medo de confessar sua opinião; é o que diz o Breve del popolo e delle Compagne di Pisa, de 1313. ${ }^{32}$ Muito sintomaticamente, os estatutos de Turim, de 1360, sob autoridade do conde, precisam que o voto secreto será a regra, exceto "in casibus nos tangentibus, partita fiant ad levandum et sedendum". ${ }^{33}$ Quer dizer, o conde se reservava o direito de saber quem poderia eventualmente estar em desacordo com seus representantes. É inútil entrar no detalhe de tudo o que a busca do segredo pôde suscitar como invenções técnicas (duas urnas com apenas uma ficha de voto, ficando as mãos mergulhadas simultaneamente em cada urna para tornar indetectável a escolha, sendo as urnas revestidas de veludo para não se ouvir o barulho da ficha ou da fava que cai, etc). ${ }^{34}$

Garantir o segredo dos votos aparece como uma obsessão dos estatutos, tão perturbadora na sua reiteração quanto na complexidade dos sistemas de eleição dos magistrados comunais. Com efeito, no regime comunal, uma grande parte da vida cívica consistia em eleger magistrados, para as funções mais variadas. Para prevenir intrigas, a via escolhida foi a da superposição dos graus eleitorais. Implicitamente, considerava-se que a multiplicação dos obstáculos entre o eleitor e o eleito era a melhor garantia para conter a vontade individual do ambicioso e limitar a intriga. Mais profundamente ainda, a complexidade dos graus visava desestruturar eventuais estratégias facciosas ou familiares, consideradas como desgastantes da ligação social..$^{35}$ Se sustentarmos que as estruturas eleitorais constituem os marcadores mais característicos de uma organização política, então é preciso admitir que, no mundo comunal, a organização política, se baseava em uma estranha mistura entre a busca do consenso e a desconfiança para com os cidadãos singulares. Tal é o sentido de acordar a multiplicação das eleições em dois ou vários turnos para determinar um colégio eleitoral chamado a escolher os magistrados. A novidade aparece desde a época consular: entre o Breve de Pisa, de 1162, que prescreve que os cônsules elegerão apenas os juízes, os diretores e os senadores e o de 1164, que prescreve que os cônsules elegerão (escolherão) um colégio eleitoral destinado a escolher, por sua vez, os futuros oficiais, se faz a passagem entre

32 Breve del popolo e delle Compagne di Pisa. In: BONAINI, F. (ed.) Statuti inediti della città di Pisa dal XII al XIV secolo Firenze, 1870, v.ll, p.529.

33 BOCCHINO, G.; BRACCO, G.; COMBA, R.; ROCCIA, R.; SERGI, G.; SETTIA, A.A. (éds.) Torino e i suoi statuti nella seconda metà del Trecento. Torino, 1981.

34 Detalhes muito completos em RUFFINI. La ragione dei più, p.258-259

35 Não pode deixar de nos impressionar essa contradição fundamental no centro dos órgãos comunais italianos: por um lado, uma vida social muito articulada em torno dos agrupamentos familiares, necessariamente hierarquizados e verticais, por outro lado, uma vida política que se esforça por colocar impedimenta institucionais para que os mecanismos de solidariedade familiar sejam limitados pela singularidade individual do cidadão. Esta distância entre realidade sociológica e construção tecnocrata é analisada especiamente nos capítulos II e III de GILLI, P. Villes et sociétés urbaines en Italie. 
a eleição direta e indireta. Tudo isto não compromete em nada o caráter aristocrático e oligárquico dos regimes que implantavam esta sutil repartição eleitoral, precisamente para eliminar as categorias indesejáveis e mitigar os riscos de monopolização dos cargos consulares por uma única família, organizando uma tensão competitiva saudável entre as várias famílias. Mas não se inventa uma tecnologia do poder que mediatize a relação entre governantes e governados, sem que isto não tenha consequências, inicialmente, em parte insuspeitas. Mais que em outros lugares na Europa, parece que entre a dominação social e o governo político, a articulação está longe de ser unívoca. Dominar não é governar, e a multiplicação das técnicas de mediação, via eleições ou assembléias deliberativas, ilustra a necessidade dos grupos dirigentes de inventar modelos institucionais que, por um lado, legitimam sua dominação criando um consenso mínimo, e, por outro lado, atenuam os riscos de captação brutal do poder por uma família, com o risco de romper o frágil equilíbrio no seio das elites. Ao que se acrescenta a considerável pressão que exerciam as autoridades supraurbanas, como o império e o papado, que obrigavam os dirigentes a compromissos ou alianças permanentes. ${ }^{36}$ Lembremos, igualmente, a desconsideração nos estatutos, exceto pela negativa, para se rejeitar o uso do processo de eleição dos magistrados ad vocem, provavelmente muito fáceis de manipular. Os anais genoveses do continuador de Caffaro explicam claramente esta situação: Frédéric II havia interditado a eleição de magistrados oriundos de comunas rebeldes no império. Ora, em 1231, Gênova elege um magistrado milanês; a cidade teve que se desculpar por meio de embaixadores, os quais explicaram que não podiam voltar atrás na sua escolha, pois havia sido prestado juramento e, sobretudo, este magistrado havia sido eleito pelos genoveses ad brevia sive ad sortem. Fosse ele eleito ad vocem, os genoveses teriam respeitado a proibição! ${ }^{37} \mathrm{O}$ processo secreto é assim um meio de ampliar o círculo dos eleitos, diluindo ficticiamente as responsabilidades. Evidentemente, a resposta não deve ter agradado muito ao imperador. O caso mais exemplar destas técnicas de eleições se concentra na escolha dos magistrados. É aí que se percebe claramente como o processo de complexificação dos processos em graus diversos ocupou o lugar de mecanismo de neutralização das tensões. Sem

36 Uma análise muito refinada das ligações entre inovação institucional, desafios econômicos, relações de classe e contexto diplomático se encontra no artigo de DIACCIATI, S. Popolo e regimi politici a Firenze nella prima metà del Duecento. Annali di Storia di Firenze, v.1, 2005. (Disponível on line: http://eprints.unifi. it/ archive/00001060/01/02 SdF 12006 Diacciati saggi.pdf). Trata-se de um estudo que articula, tanto quanto as fontes o permite, a política, $\overline{0}$ social e o econômico. Aí se revelam como as inovações institucionais tomam lugar em resultados de compromisso. Na nossa perspectiva reiteramos, sobretudo, nos anos 1240, a emergência progressiva, caótica e instável de uma "maioria de governo", composta de elementos culturalmente e socialmente muito heterogêneos, em que coabitam guelfos e gibelinos, populares e milites (estes dois binômios não sendo inteiramente passíveis de superposição). Para que a alquimia social sobrevivesse, eram imperativamente necessárias "formulas de governamentalidade" inovadoras.

37 BELGRANO,L.T. e IMPERIALE,C. (éds) Annali genovesi, a.1231. Roma: Fonti per la storia d'Italia, 1901, t.III, p.61. 
a emergência de um grupo intermediário de eleitores cuja função era a de propor uma lista de elegíveis, os conselhos teriam sido incapazes de chegar a um acordo sobre um único nome. Este colégio de compromissários, para utilizar o termo usado nos capítulos canônicos, era frequentemente sorteado: não havia, portanto, nenhum mandato no sentido próprio da palavra, isto é, nenhum elo unia estes eleitores a seus eleitos, que pareciam viver em regime de desconfiança. O objetivo do sorteio era, evidentemente, quebrar a cadeia dos interesses particulares; daí, a natureza profundamente diferente dos regimes consulares e o dos magistrados: o primeiro é, de certa forma, imanente às famílias dirigentes e constitui uma manobra que regula provisoriamente as tensões entre famílias dominantes; o segundo Ihes é transcendente, já que se trata doravante de transferir a um terceiro, denominado potestas (e observaremos o uso deste termo que remete não à essência do dominium político - a palavra latina teria sido aucto-ritas -, mas à prática do jogo das instituições: a potestas sendo o que atualiza a auctoritas), a gestão ordinária da cidade. ${ }^{38}$ Esta passagem da imanência à transcendência não designa simplesmente a gênese do político? Para que a "transcendência" fosse completa, seria preciso dissociar a escolha dos magistrados a serem eleitos da própria natureza dos eleitores: o sorteio dos eleitores impunha-se então como solução inevitável. Tudo acontece como se a multiplicação dos graus eleitorais visasse redistribuir as cartas em cada etapa e obter um tipo de quintessência do cidadão para a depuração sucessiva (mas da depuração "química" à depuração política, o passo é rapidamente dado, como o mostram os regimes do povo na segunda metade do século XIII e sua política de exclusão que visam ajustar o perímetro da cidadania ao perímetro da adesão partidária). ${ }^{39}$

Era preciso também assegurar a total neutralização dos eleitores, como evidencia a criação de conclaves laicos para a eleição dos magistrados, com o objetivo de subtrair o colégio eleitoral das múltiplas pressões. Uma das primeiras documentações data de 23 de março de 1223, em Plaisance, onde a crônica anônima relata de maneira detalhada, como o magistrado Sainte fez aprovar, por cem cavaleiros da cidade e por cem populares, a eleição de oito cônsules (quatro para cada entidade) que foram fechados em um quarto comum até sábado, sem comer nem beber para designar o novo magistrado. O fracasso desta tentativa incita o magistrado a reiterar a medida fazendo selecionar por sessenta membros dos dois partidos, seis novos eleitores, que foram fechados de domingo à sexta-feira seguinte,

38 A melhor apresentação da revolução do magistrado está em ARTIFONI, E. I podestà itineranti e l'area comunale piemontese. Nota su uno scambio ine-guale. In: VIGUEUR, J.-C. Maire. (éd.) I podestà dell'Italia comunale. Roma, 2000, p.23-45. Apesar de um título limitado, a contribuição de Artifoni coloca de maneira notável os desafios institucionais da invençãdo magistrado.

39 Ver o estudo de MILANI, G. L'esclusione dal Comune: conflitti e bandi politici a Bologna e in altre citta italiane tra 12. e 14. secolo. Roma, 2003 e GILLI, P. Villes et sociétés urbaines en Italie. 
segundo o mesmo regime..$^{40} \mathrm{O}$ princípio do conclave laico se propaga por inúmeras cidades, em perfeita concordância cronológica com as propostas dos decretalistas como Alanus Anglicus, ${ }^{41}$ e sua institucionalização se deu pela bula Ubi periculum, de Grégoire X em 1274, que regulou a eleição pontifical.

Lembremos igualmente que o sorteio tinha mais frequentemente como objeto a designação dos eleitores que a dos eleitos. O que isto significa? Poderíamos idealizar que o processo não é tão absurdo assim e que reflete mesmo um tipo de cálculo matemático. No fundo, podemos postular que cada eleitor sabia avaliar quem estaria apto a cumprir a tarefa dada, melhor que ele próprio a cumpriria. A velação do sorteio dos eleitores se reequilibra assim e reduz as eventuais injustiças. Além disto, politicamente, o negócio é muito bem amarrado: se o sorteio garante a rotatividade e a repartição dos ofícios com imparcialidade suficiente, está, no entanto assegurado, que os equilíbrios políticos não serão alterados por este sorteio, já que os eleitores designarão um candidato que pertencerá a sua vertente política. Logicamente, o sorteio nunca impediu o governo de um partido, nem o enfraquecimento da soberania da assembleia do povo. Ao contrário, permitiu um tipo de eufemização do desapossamento político, fazendo passar por processo técnico o que era um meio de eliminar grupos sociais julgados inassimiláveis ao regime. Eu lembraria, entretanto, que o desenvolvimento do processo do sorteio nas comunas se produz no momento em que a igreja o proscreve: em 1223, Honorius III o proíbe nas eleições eclesiásticas ${ }^{42} \mathrm{~A}$ indeterminação que a sorte introduz é exatamente o contrário da escolha inspirada e voluntária que os eleitores "canônicos" devem fazer. É preciso, aliás, insistir sobre a extraordinária variedade dos processos de sorteio, cujo nome variava nas fontes (ad brevia, per apodixias ou politias, ad carticellas). Os conselheiros ou eleitores de segundo grau tiravam um pequeno papel sobre o qual estava indicado o nome de um ofício e eles deviam então designar o feliz eleito.

40 Annales italici aevi suevici. M.G.H., v.XVIII, G.H. Editado por Pertz. Stuttgart, p.438-439, 1863. "Die Jovis, 10 kal. Aprilis, predictus potestas Cremone centum de militibus societatis militum fecit accidere, de quibus a societatis consulibus militum quatuor pro podestate comunis eligenda petivit, et totidem a popularibus. Qui consules dederunt eis [lista dos nomes] qui steterunt in camera communis pro potestate eligenda usque ad diem sabbati proximum, non comedentes nec bibentes. Qui cum illis, qui erant pro populo, accordari minime potuerunt. Qui cum illis, cum in electione potestatis se accordare cum popularibus non potuissent, die dominica sequenti predictus potestas Cremone precipit consulibus militum, ut darent ei 60 milites, et ex populo habuit totidem; de quibus militibus tres fuerunt electi ad brevia et totidem de popularibus, qui ea die in communis camera fuerunt pro potestate eligenda inclusi. Hii tres pro militibus, scilicet [lista dos nomes] qui steterunt cum popularibus in ipsa camera usque ad diem Veneris proximum... Ea vero die divina misericordia concorditer eligerunt in potestatem communis Placentie dominum Negrum Marianum". Ver RUFFIN. La ragione dei più, p.180-181.

41 Ver a edição da glosa de Alanus Anglicus au canon Licet, no seu Apparatus à la Compilatio I, glosa tirada dos mss Vat. Lat 1377 e Vat. Lat. 2509: "Quid ergo fiet si nullo modo due partes possunt consentire, recurratur ad brachium seculare, arg. di. XVIII nec licuit, XVIII, q. V de Liguribus, hoc modo quod veniant romani et includant cardinales in conclavi et compellant eos consentire": Ruffin, E. (éd.) La ragione dei più, p. 195.

42 Chronicon minor Ephordensi, a.1224. MGH, Scriptores Rerum Germanicarum in Usum Scholarum, Hannover-Leipzig, v.XXIV, p.650, 1899: "hic papa Honorius sortis usum in electionibus perpetuo prohibet et condempnat, scilicet ne prelati per sortes eligantur". Cf RUFFIN, E. La ragione dei più, p.299. 
Para maior clareza, e porque isto não tem o mesmo sentido político, é preciso distinguir entre o sorteio dos eleitores e o sorteio dos oficiais eleitos, sendo o segundo ainda raro no século XIII. O sorteio dos oficiais eleitos é, finalmente, o sistema que oferecia mais garantia para a perpetuação de uma classe de governo ampliada e reduzia paradoxalmente a sorte diante da escolha voluntária: ele encontrou, aliás, sua máxima expressão no sistema de imbor-sazione florentina que atingiu sua maturidade em 1330, já que a gama dos elegíveis tinha sido drasticamente coibida pelo colégio eleitoral que estabelecia a lista dos elegíveis, a qual devia ser aprovada por $2 / 3$ do colégio. ${ }^{43}$ No fundo, as manipulações de escrutínios, na medida em que eles não se apoiavam em bases territoriais modificáveis (um bairro ou um distrito continua sendo um bairro ou um distrito; a Idade Média italiana não conhece gerrymandering), podiam se fazer, seja por modificação da geometria eleitoral (o que prevaleceu na época do Popolo triunfante quando havia adequação entre a adesão a um partido e a integração na cidadania por uma política de exclusão), seja pela restrição dos elegíveis às magistraturas, técnica que prevaleceu no século XIV, em Florença, ou em Pérouse, em 1342. Esta evolução dos processos eleitorais ilustra assim um aspecto não negligenciável da cultura política: enquanto que a primeira situação, do tipo do Secondo popolo florentino ou do tipo de Bolonha nos Ordinamenta sacra et sacratíssima, justificava a exclusão (dos adversários) em nome da integração (de todos os outros) e considerava de fato todos os cidadãos devidamente patenteados como eleitores, a segunda visava mais claramente criar uma classe de governo, dividindo violentamente a civitas (no duplo sentido latino de cidade e cidadania), tornada, por grande parte de seus membros, mais virtual que real. Não é surpreendente que estas questões eleitorais tenham sido percebidas como vitais: em 24 de novembro de 1292, em uma única sessão do conselho das doze artes maiores florentinas, não menos que 24 reformas eleitorais para a designação dos priores foram examinadas. ${ }^{44}$

Como conclusão deste trabalho, eu gostaria de colocar em evidência alguns pontos de alcance mais geral. As técnicas eleitorais e deliberativas nos dizem muito sobre a concepção das relações políticas na sociedade comunal, sobretudo se as relacionarmos ao que nos ensinam as análises contemporâneas da sociologia da decisão.

No interior da assembléia ou do colégio eleitoral existe uma separação insuperável entre o processo eleitoral e a deliberação: o primeiro, essencial

43 GUIDI, G. I sistemi elettorali del comune di Firenze nel primo Trecento. II sorgere della elezione per squittino (13001328). Archivio Storico Italiano, n. 130, p.345-407, 1972 e GUIDI, G. I sistemi elettorali agli uffici della città-repubblica di Firenze nella prima metà del Trecento (1329-1349). Archivio Storico Italiano n. 135, p.373-424, 1977; ver também KLEIN, F. (ed.) I consigli della Repubblica fiorentina. Libri fabarum XVII (1338-1340). Firenze, 1995.

44 KLEIN, F. Introduzione. In: I Consigli; GUIDI, G. I sistemi elettorali del comune di Firenze nel primo Trecento, p.353 e seg. 
na medida em que visa renovar a permanência do pessoal político e administrativo, não oferece nenhum lugar na busca de critérios objetivos de seleção deste pessoal; inversamente, a deliberação nos conselhos, sobre as grandes questões da vida comunal, quase não entra nas preocupações dos redatores dos estatutos ou dos cronistas.

De fato, uma vez constituída a assembleia ou o colégio eleitoral, permanece para sempre inaccessível o essencial: como operaram as agregações de preferências individuais que fazem a escolha majoritária? Qual foi o peso da deliberação e da argumentação na tomada de decisão final? Como a politização do espaço público, que transformava o indivíduo em cidadão ativo, pôde coabitar com uma estrutura de representação de natureza pré-moderna - entenda-se por aí as formas de representação nas quais a integração prévia em uma corporação (de bairro, de artes ou de armas, até mesmo de partido) privava o individuo de uma parte de seu livre arbítrio, e o transformava inicialmente em representante do grupo munido de um mandato imperativo (mesmo se o conceito nunca é explicitado nas fontes da época) ${ }^{45} \mathrm{~A}$ representação política medieval pela qual o populus se reduzia à soma aritmética de seus corpos intermediários torna difícil a apreciação das margens de discussão dos "eleitos".

Continuamente imbricadas - as funções legislativas e deliberativas, próprias à ação política e a designação dos magistrados, própria à atividade administrativa - as instituições representativas italianas não nos simplificaram a tarefa. A razão volta ao sentido e à função da representação política percebida então como coextensiva à própria comuna. A experiência do magistrado teria podido levar à separação entre uma esfera de decisão indivisível nos diferentes conselhos e uma esfera administrativa indivisível na familia magistral.

O enfraquecimento do magistrado designa, ao contrário, o forte retorno de uma lógica política que faz da comuna um todo unificado, cujo ideal do bem comum e a condenação das facções levavam à concentração monopolista das atividades poli administrativas, inicialmente no seio dos conselhos, depois nas mãos de algumas famílias, que manipulavam os processos eleitorais. Esta é toda a história política do século XIV italiano.

45 Ver DUSO, G. La rappresentanza politica. Genesi e crisi del concetto. Milano, 2003, p.61-64. O fato é que é difícil conhecer na Idade Média italiana os processos de agregação das preferências que fazem o voto majoritário. Cabe à Revolução Francesa e a Sieyès por ter teorizado e colocado em prática a idéia que só poderia haver representação dos interesses pessoais e de interesse geral na exclusão, portanto, nos interesses dos corpos intermediários. 